\title{
Evaluation of Post-Placental IUD Insertion during Cesarean Section at a Tertiary Care Hospital in Egypt
}

\author{
Amal Elsokary, Ahmed Elkhyat, Shereef Elshwaikh* \\ Department of Obstetrics and Gynecology, Tanta University, Tanta, Egypt \\ Email: ^frommetou35@gmail.com
}

How to cite this paper: Elsokary, A., Elkhyat, A. and Elshwaikh, S. (2020) Evaluation of Post-Placental IUD Insertion during Cesarean Section at a Tertiary Care Hospital in Egypt. Open Journal of Obstetrics and Gynecology, 10, 516-525.

https://doi.org/10.4236/ojog.2020.1040046

Received: March 13, 2020

Accepted: April 10, 2020

Published: April 13, 2020

Copyright () 2020 by author(s) and Scientific Research Publishing Inc. This work is licensed under the Creative Commons Attribution International License (CC BY 4.0).

http://creativecommons.org/licenses/by/4.0/

\begin{abstract}
Objectives: To evaluate the efficacy of post placental IUD insertion during cesarean section. Background: IUD could be applied to the female after delivery of placenta during cesarean section, it had many advantages as the female is under anesthesia so no extra manipulation needed, decrease pain, and also the female at the period of delivery had high motive for family planning. Post placental IUD insertion also had many disengages like bleeding and displacement. Material and methods: A randomized controlled study was conducted at tertiary care hospital (Tanta University Hospital) in the period from Jan, 1, 2017 to May 31 2019. Two groups of patients were selected; each group included 60 patients with desire of birth control. The group I was subjected to post-placental intrauterine device (IUD) insertion during cesarean section and group II was subjected to interval IUD insertion (3 months after cesarean delivery). The type of IUD used was cupper-T IUD, both groups were assessed as regard to time of cesarean section (CS), amount of postoperative bleeding, postoperative pain, occurrence of infection, any displacement of IUDs, failure of contraception and patients' satisfaction. Results: The demographic data were comparable in both groups. The duration of cesarean surgery was slightly prolonged in the study group. The infection, puerperal bleeding, and displacement of IUDs were not significantly different in both groups. The discontinuation rate after 12 months was $13.72 \%$ in study group compared to $16.66 \%$ in the control group. The satisfaction rates in both groups were $90.20 \%, 91.67 \%$ in study and control groups respectively. The expulsion rates were $3.92 \%$ and $0.00 \%$ in the study and control groups respectively. Pregnancy on top of IUD was $1.96 \%$ in study group and $4.17 \%$ in control group with $\mathrm{p}$ value $=0.949$. Conclusion: Post-placental IUD insertion is found to be safe, easily applied during cesarean section with slight prolongation of cesarean section duration. Post-placental IUD insertion is
\end{abstract}


also effective, with few complications compared to interval IUD insertion. This modality of insertion was accepted by the great majority of patients being painless and at the same time of surgery with no added cost or maneuver and utilizing the enthusiasm of patients for immediate contraception. The continuation rates are good in the study follow up duration.

\section{Keywords}

Intrauterine Device, Post-Placental Insertion, Contraception, Displacement, Pregnancy Spacing, Time of Insertion

\section{Introduction}

Intrauterine device (IUD) is considered one of the most acceptable and effective contraceptive methods used. It is widely accepted and used in Egypt at a large scale than any other type of contraception with many advantages over the other types of contraceptive methods including long acting hormonal methods [1] [2].

Despite IUD complications, it remains the most accepted method, as it has many advantages like being non-coital related, had no systemic complications, of long duration and reversible with rapid return of fertility after its removal [2].

The complications of IUD include heavy menstrual bleedings, menstrual irregularities and infection complications which could be minimized by using strict aseptic techniques during insertion [3]. The most distressing complication is the displacement of IUD, especially if this displacement was extra-uterine, as the patient needs a surgical maneuver (endoscopic usually) for extraction of this IUD. Displacement of IUDs puts a financial and psychological burden to the patient also increases the risk of unwanted pregnancies and its related risks [4].

Displacement of IUD occurs mainly during its insertion, and occurs mainly due to rough or wrong technique; also IUD insertion at a wrong timing may increase risk of IUD displacement. So it is very important to insert IUDs at the proper time with the proper technique [4].

Timing of insertion of IUD after cesarean section is a matter of debate, some gynecologists insert IUDs during cesarean section after placental removal, while other gynecologists prefer insertion of IUDs after an interval either immediately after puerprium (42 days), or after 6 months post-cesarean section, but the majority inserts IUDs after 3 months from cesarean section [5].

The idea of waiting a three-month interval after cesarean section is to assure that the scar had completely healed and the uterus involutes completely to its pre-pregnancy size. The drawbacks of waiting this long interval are poor accessibility of the cervix which may be pulled upward in some cases of repeated cesarean section and loss of self-enthusiasm for rapid contraception after delivery [6].

The intraoperative insertion of IUD had many controversies, and its advantages over late insertion are not settled yet. This study aimed to evaluate the effi- 
cacy of post-placental insertion of IUD during cesarean section in comparison to interval (three-month) insertion.

\section{Patients and Methods}

Study design: randomized controlled study.

Setting: This was conducted at tertiary care hospital (Department of Obstetrics and Gynecology of Tanta University-Egypt), in the period from Jun, 1, 2017 to May 312019.

Eligibility: Recruited patients were 144 cases. After selection according to inclusion and exclusion criteria, 120 patients were eligible. Inclusion criteria included: 1) Pregnant women attending for elective or emergency cesarean section, 2) patient desiring immediate contraception. The exclusion criteria included: 1) Upper segment or classical cesarean scar, 2) previous myomectomy scar, 3) cesarean on top of placenta previa or placenta accrete, and 4) evident infections at time of cesarean section as chorioamnoitis.

Randomization and allocation: Selected patients $(n=120)$ were randomly allocated into 2 groups; group I (Study group) with intra-operative post-placental insertion of IUD and group II (Interval insertion control group) with delayed insertion of IUDs after a three-month interval following cesarean section. The type of IUD used is Cupper-T IUD, Randomization was done using specific computer programs with numbers distributed in closed envelops. Allocation was equal 1:1 with alternate allocation. Opening envelopes didn't change allocation.

Sample size calculation: The sample size was calculated using Epi-Info 7 specific program. $\mathrm{H}_{0}$ was postulated to indicate that immediate insertion is better than delayed insertion and had high enthusiasm for immediate postpartum contraception. The calculated sample size was 120 patients.

\section{Interventions:}

Group I (study group): $(\mathrm{n}=60)$

1) Lower segment cesarean section by standard technique.

2) At cesarean insertion, place the IUD at the top of the uterine fundus manually (Cupper T380).

3) Before closing the uterine incision, place the strings in the lower uterine segment.

4) Strings are passed through the cervix with IUD insertion tube.

Group II (Interval insertion control group): $(\mathrm{n}=60)$

1) Lower segment cesarean section by standard technique.

2) A three-month later, IUD was inserted (cupper T380) by the standard withdrawal technique.

Methods: All patients' demographic data were taken, type of cesarean, duration of surgery, post-operative bleeding, pain, infection, failure rate and patient's satisfaction (known by simple questioning of patient, and the presence or absence of any complaint regarding IUD). IUD displacement was checked by Ultrasound examination at 3 months, 6 months and 12 months intervals in both 
groups.

Outcomes of study: primary outcomes include: 1) displacement of IUD: intrauterine or extrautreine by ultrasound, 2) failure of contraceptive method and 3) discontinuation of the method, 4) patient satisfaction known by simple questioning of patient (satisfied or not), and the presence or absence of any complaint regarding IUD.

The secondary outcomes include: 1) duration of surgery: from the skin incision till closure of skin wound, 2) amount of post-operative bleeding: subjective estimation depending on patients and drop of hemoglobin, 3) pain: with exclusion of first postoperative day depending on visual analogue scale (VAS) with score greater than 45,4$)$ infection: from either mild skin infection to sever puerperal sepsis.

Ethical approval and clinical trial registration: This study was approved by local ethical committee of Tanta University before start of this study and registered on UMIN-CTR under the code of UMIN000031035. All patients were informed about study design, interventions, and risks. All patients signed written consent. Privacy and security were maintained all over the duration of study.

Statistical methods: The data were gathered and analyzed by SPSS, version 18 (USA, Chicago). The statistical tests used were mean, standard deviation, Chi-square and test of significance. $\mathrm{P}$ value was considered to be significant if $\leq 0.005$.

\section{Results}

This study initially enrolled 144 patients who were assessed for eligibility. After selection according to inclusion and exclusion criteria for eligibility, 120 patients were enrolled in this study. The flow of patients during the study period was shown in Figure 1. The demographic data of enrolled patients were demonstrated in Table 1.

The duration of surgery was prolonged in the study group $(35.2 \pm 2.70) \mathrm{mi}$ nutes versus control group $(28.03 \pm 3.04)$ minutes. The prolonged duration of surgery was due to the added time of IUD insertion. There was no difference in pain on visual analogue scale (VAS) between the 2 groups ( $\mathrm{p}$ value $=0.769$ ). $\mathrm{Pu}$ erperal bleeding was the same in both groups as regard moderate and severe bleeding with $\mathrm{p}$ value $=0.793$. The abnormal uterine bleeding occurring after puerprium was also not significant between both groups ( $\mathrm{p}$ value $=0.751$ ) as shown in Table 2.

The IUD displacement occurring either intra-uterine or extra-uterine was not significant in both groups ( $\mathrm{p}$ value $=0.523$ ) but expulsion was more in the study group. Infection rates were not significant in both groups as regard puerperal infection, wound sepsis or pelvic inflammatory disease (PID). Most patients were satisfied in both groups by the method of contraception with nearly similar rates of satisfaction ( $90.20 \%$ in study group versus $91.67 \%$ in control group) as shown in Table 2.

Discontinuation of method after 6 months occurred in 3 cases in study group 
versus 4 cases in control group, and after 12 months the number of cases became 7 in study group versus 8 cases in control group The threads are less felt in the study group compared to the control group with increasing numbers of patients feeling threads by time $6 / 51(11.76 \%)$ at 3 months, became $11 / 51(21.57 \%)$ at 6 months and became $21 / 51$ (41.17\%) at 12 months. Pregnancy on top of IUD was similar in both study and control group as shown in Table 2.

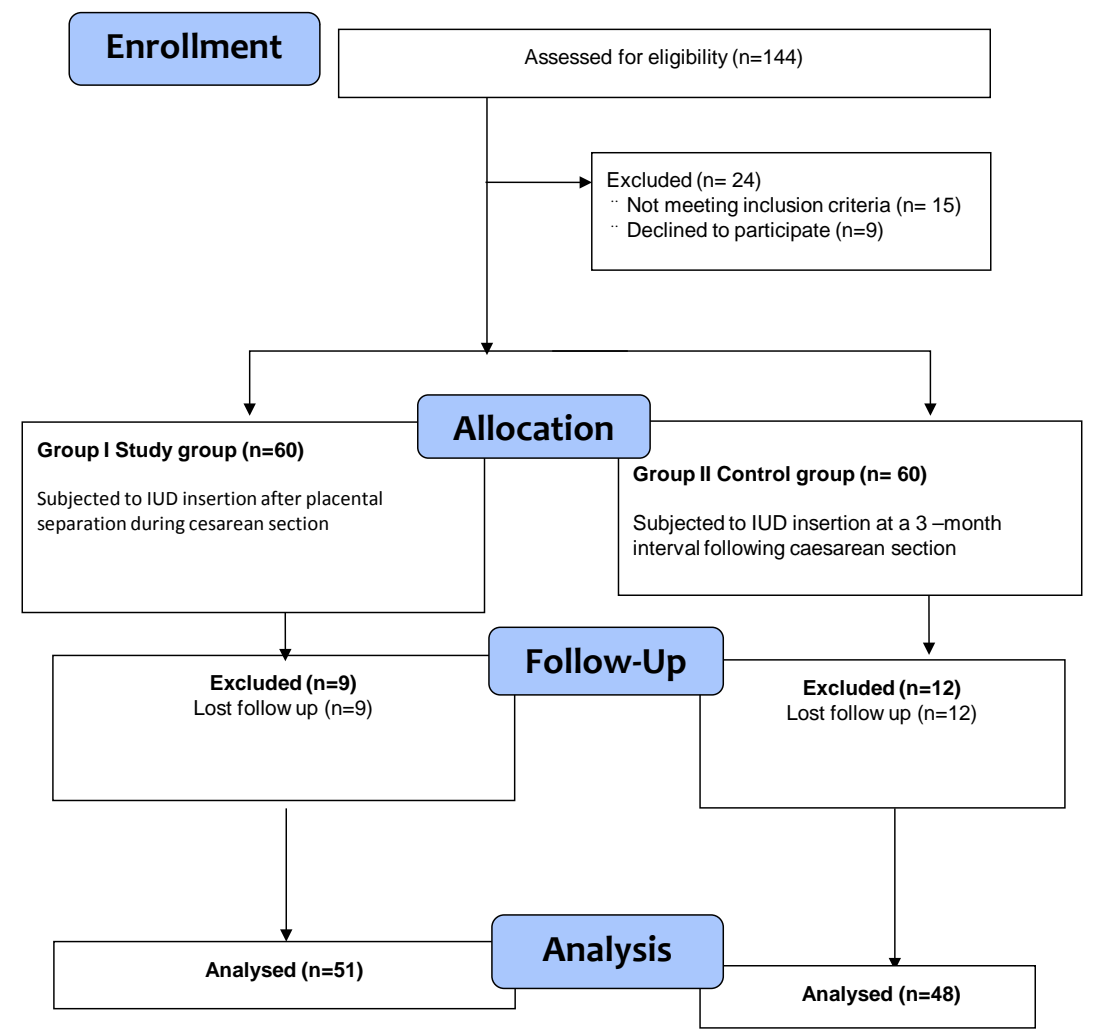

Figure 1. Allocation and flow of cases in both study groups.

Table 1. Demographic characteristics of enrolled patients in both groups.

\begin{tabular}{|c|c|c|c|c|}
\hline & $\begin{array}{c}\text { Group I } \\
\text { (Study group) } \\
(\mathrm{n}=51)\end{array}$ & $\begin{array}{c}\text { Group II } \\
\text { (Control group) } \\
(\mathrm{n}=48)\end{array}$ & Chi-Square & $\mathrm{p}$ value \\
\hline \multicolumn{5}{|l|}{ Age (years) } \\
\hline Range & $19-41$ & $19-42$ & \multirow{2}{*}{0.523} & \multirow{2}{*}{0.301} \\
\hline Mean \pm SD & $29.6 \pm 5.65$ & $28.73 \pm 7.09$ & & \\
\hline \multicolumn{5}{|l|}{ Parity } \\
\hline Range & $1-6$ & $1-6$ & \multirow{2}{*}{0.098} & \multirow{2}{*}{0.460} \\
\hline Mean \pm SD & $2.37 \pm 1.22$ & $2.33 \pm 1.39$ & & \\
\hline \multicolumn{5}{|l|}{ Gravidity } \\
\hline Range & $1-5$ & $1-5$ & \multirow{2}{*}{0.267} & \multirow{2}{*}{0.394} \\
\hline Mean \pm SD & $2.41 \pm 2.04$ & $1.96 \pm 1.03$ & & \\
\hline \multicolumn{5}{|c|}{ Gestational age (weeks) } \\
\hline Range & $34-41$ & $32-42$ & \multirow{2}{*}{0.654} & \multirow{2}{*}{0.257} \\
\hline Mean \pm SD & $37.77 \pm 1.40$ & $37.47 \pm 2.08$ & & \\
\hline \multicolumn{5}{|c|}{ No of cesarean scars } \\
\hline Range & $1-4$ & $1-4$ & \multirow{2}{*}{0.343} & \multirow{2}{*}{0.366} \\
\hline Mean \pm SD & $1.9 \pm 0.711$ & $1.83 \pm 0.79$ & & \\
\hline
\end{tabular}


Table 2. Outcome results in both groups of patients.

\begin{tabular}{|c|c|c|c|c|}
\hline & $\begin{array}{c}\text { Group I } \\
\text { (Study group) } \\
(\mathrm{n}=51)\end{array}$ & $\begin{array}{c}\text { Group II } \\
\text { (Control group) } \\
(\mathrm{n}=48)\end{array}$ & Chi-Square & $\mathrm{p}$ value \\
\hline \multicolumn{5}{|l|}{ Duration of surgery (minutes) } \\
\hline Range & $35-45$ & $25-35$ & \multirow{2}{*}{2.911} & \multirow{2}{*}{$0.002^{*}$} \\
\hline Mean \pm SD & $35.2 \pm 2.70$ & $28.03 \pm 3.04$ & & \\
\hline Significant Pain on VAS ${ }^{*}$ & $7 / 51(13.73 \%)$ & $6 / 48(12.50)$ & 0.032 & 0.857 \\
\hline Puerperal bleeding ${ }^{\star}$ Moderate & $7 / 51(13.73 \%)$ & $7 / 48(14.58 \%)$ & 0.015 & 0.904 \\
\hline Severe & $2 / 51(3.92 \%)$ & $1 / 48(2.08 \%)$ & 0.282 & 0.595 \\
\hline Abnormal uterine bleeding* & $5 / 51(9.80 \%)$ & $6 / 48(12.50 \%)$ & 0.181 & 0.670 \\
\hline \multicolumn{5}{|l|}{ IUD displacement* } \\
\hline Intra-uterine & $1 / 51(1.96 \%)$ & $2 / 48(4.17 \%)$ & 0.407 & 0.523 \\
\hline Expulsion & $2 / 51(3.92 \%)$ & $0 / 48(0.00 \%)$ & 1.901 & 0.168 \\
\hline \multicolumn{5}{|l|}{ Infection rate ${ }^{\star}$} \\
\hline Puerperal sepsis & $4 / 51(7.84 \%)$ & $4 / 48(8.33 \%)$ & 0.008 & 0.929 \\
\hline Wound sepsis & $4 / 51(7.84 \%)$ & $1 / 48(2.08 \%)$ & 1.695 & 0.193 \\
\hline PID & $1 / 51(1.96 \%)$ & $1 / 48(2.08 \%)$ & 0.002 & 0.966 \\
\hline \multicolumn{5}{|l|}{ Satisfaction* } \\
\hline Satisfied & $46 / 51(90.20 \%)$ & $44 / 48(91.67 \%)$ & \multirow{2}{*}{0.064} & \multirow{2}{*}{0.800} \\
\hline Unsatisfied & $5 / 51(9.80 \%)$ & $4 / 48(8.33 \%)$ & & \\
\hline \multicolumn{5}{|l|}{ Discontinuation of method ${ }^{*}$} \\
\hline 3 months & $0 / 51(0.00 \%)$ & $0 / 48(0.00 \%)$ & 0.000 & 0.000 \\
\hline 6 months & $3 / 51(5.88 \%)$ & $4 / 48(8.33 \%)$ & 0.224 & 0.636 \\
\hline 12 months & 7/51 (13.72\%) & $8 / 48(16.66 \%)$ & 0.166 & 0.683 \\
\hline \multicolumn{5}{|l|}{ Threads felt ${ }^{*}$} \\
\hline 3 months & 6/51 (11.76\%) & $40 / 48(83.33 \%)$ & 50.405 & $<0.001^{*}$ \\
\hline 6 months & $11 / 51(21.57 \%)$ & $42 / 48(87.50 \%)$ & 42.773 & $<0.001^{*}$ \\
\hline 12 months & $21 / 51(41.17 \%)$ & $42 / 48(87.5 \%)$ & 22.93 & $<0.001^{*}$ \\
\hline \multicolumn{5}{|l|}{ Pregnancy on top ${ }^{*}$} \\
\hline 3 months & $0 / 51(0.00 \%)$ & $0 / 48(0.00 \%)$ & 0.000 & 0.000 \\
\hline 6 months & $1 / 51(1.96 \%)$ & $2 / 48(4.17 \%)$ & 0.407 & 0.523 \\
\hline 12 months & $1 / 51(1.96 \%)$ & $2 / 48(4.17 \%)$ & 0.407 & 0.523 \\
\hline
\end{tabular}

As regard complications, there was insignificant relationship between both groups as regards infection, bleeding, displacement and failure of the method. Actually both groups had low complications rate, with only one case in each group suffered from major complication (PID) and both cases managed by conservative management successfully.

\section{Discussion}

Intrauterine contraceptive device (IUD) is considered the most acceptable and widely used methods of contraception, being safe, cheap, long acting and reversible. More over IUDs related complications could be avoided by aseptic technique during its insertion, and proper method for its insertion [7].

There is still a debate about the best timing of IUD insertion after cesarean delivery. Some gynecologists prefer its insertion during cesarean section [8] [9] 
[10], while others prefer interval insertion, 3 months after cesarean section [11] [12] [13]. In the current study, post-placental insertion of IUDs was similar to interval group as regard bleeding, pain, displacement and infection rates.

There is a significant difference between both groups regarding the time of cesarean section with mean time of $(35.2 \pm 2.70,28.03 \pm 3.04)$ in group I and group II respectively, with $\mathrm{p}$ value of 0.002 . This prolongation in study group was due to the duration of IUD insertion.

Post placental insertion of IUD had advantages of being painless procedure as it is done under anesthesia, while interval insertion of IUD after cesarean is painful. More over enthusiasm of patients in the immediate postpartum period was found to be higher than delayed IUD insertion group. These advantages make this method of insertion getting more popular and widely accepted by many gynecologists and patients [8] [9] [10].

In the current study, the intrauterine displacement was slightly higher in interval group (Figure 2) than study group (4.17\% versus $1.96 \%$ respectively). While the expulsion rate was also slightly higher in the study group than interval group (3.92\% versus $0.00 \%$ respectively), the overall displacement rates were not significantly different in both groups. Caliskan et al. (2003) evaluated the risk of IUD displacement on 8343 women. They found that 18 female during the study suffered from uterine perforation. The risk of perforation was less in post placental IUD insertion than in interval insertion group [6]. In the current study no cases of perforation occurred due to experience of the operating team with the techniques of IUD insertion.

Pregnancy rates on top of IUDs in both groups were similar in both groups. Şevki Ç. et al. (2011) conducted a similar study and they found that there were no serious complications from post placental IUD insertion, with only one case of pregnancy on top of IUD inserted immediate post-placental out of 245 cases. They also reported that spontaneous expulsion of IUD was $2.4 \%$, while expulsion in the current study was $3.92 \%$. This difference is owing to small sample size in the current study [14]. Other studies reported higher expulsions rates up to $10.68 \%$ [15], and $17 \%$ [16].

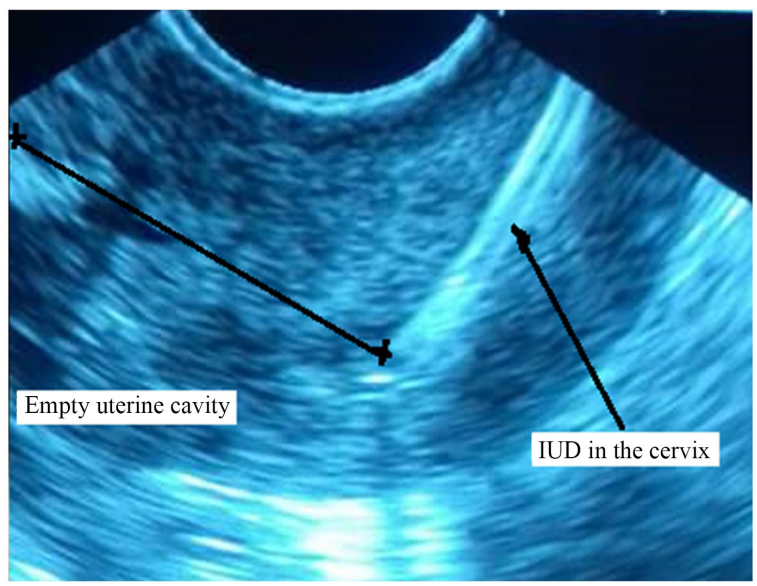

Figure 2. Intrauterine displaced IUD (cervical IUD). 
Infection rates and types were also similar in both study and control group. Similar results were obtained by Welkovic et al. (2001) where they found that 5 cases out of 245 had endometritis in the post-placental-IUD group (3.4\%) and 7 cases out of 157 women without IUD insertion (4.6\%) ( $\mathrm{p}=0.40)$ [17]. Evelyn $\boldsymbol{e t}$ al. (2012) recorded similar results in their cohort study on 43 women and they concluded that immediate post placental IUD insertion at the time of cesarean delivery is safe and acceptable [18].

The undescended threads after one year of follow up were more in the study group where 30 cases not feeling threads compared to 6 cases only not feeling threads in the control group, with p-value of $<0.001$. Similar results were obtained by Hooda et al. (2016) where strings were high in $38 \%$ of cases in the post-placental insertion group with highly significant difference between both groups $(\mathrm{p}=0.001)$ [19].

In the current study, the discontinuation rate at 3, 6, 12 month of follow up periods were similar in both groups. The main causes of discontinuations were infections, bleeding and desire of pregnancy. The satisfaction of cases with IUD was high in both groups with $90.20 \%$ and $91.67 \%$ satisfaction rates in study and control groups respectively. The same results were obtained by Levi et al. (2015) where most women in both groups were satisfied with their IUDs and satisfaction rates in the intra-cesarean group, 92\% (36/39) and 100\% (30/30) of the women in the interval group. The same was concluded by Heller et al. (2017) [20] [21].

The study had a few limitations, including missed cases in follow up period, availability of IUD during emergency cesarean section and some cases who were randomly allocated in group 2, after the three months period, changed their mind and refused to use IUD and preferred another method for contraception usually Combined contraceptive pills.

\section{Conclusions}

Intrauterine device is widely popular and accepted long acting contraceptive method. Post-placental IUD insertion is found to be safe, easily applied during cesarean section with slight prolongation of cesarean section duration. Post-placental IUD insertion is also effective, with few complications compared to interval IUD insertion.

This modality of insertion was accepted by the great majority of patients being painless and at the same time of surgery with no added cost or maneuver and utilizing the enthusiasm of patients for immediate contraception. The continuation rates are good in the study follow up duration.

\section{Conflicts of Interest}

No conflicts of interests are present.

\section{References}

[1] Hala, I. (2012) Contraception Use among Egyptian Women: Results from Egypt Demographic and Health Survey in 2005. Journal of Reproduction \& Infertility, 13, 
167-173.

[2] Cleland, J., Ali, M., Benova, L. and Daniele, M. (2017) The Promotion of Intrauterine Contraception in Low- and Middle-Income Countries: A Narrative Review. Contraception, 95, 519-528. https://doi.org/10.1016/j.contraception.2017.03.009

[3] Aoun, J., Virginia, A., Stovall, D.W., Casey, B. and Gomez-Lobo, V. (2014) Effects of Age, Parity, and Device Type on Complications and Discontinuation of Intrauterine Devices. Obstetrics \& Gynecology, 123, 585-592. https://doi.org/10.1097/AOG.0000000000000144

[4] Sunder, G. and Snigdha, G. (2016) Displaced Intrauterine Device: A Retrospective Study. The Journal of Medical Research, 2, 41-43.

[5] Goldstuck, N.D. and Steyn, P.S. (2017) Insertion of Intrauterine Devices after Cesarean Section: A Systematic Review Update. International Journal of Women's Health, 9, 205-212. https://doi.org/10.2147/IJWH.S132391

[6] Caliskan, E., Öztürk, N., Dilbaz, B.Ö. and Dilbaz, S. (2003) Analysis of Risk Factors Associated with Uterine Perforation by Intrauterine Devices. The European Journal of Contraception \& Reproductive Health Care, 8, 150-155. https://doi.org/10.1080/ejc.8.3.150.155

[7] Dawood, A.S. and Dawood, A.S. (2017) Awareness, Attitude and Preference of Long-Acting Reversible Contraceptives by Tanta University Contraceptive Clinic Attendants. International Journal of Reproduction, Contraception, Obstetrics and Gynecology, 6, 3725-3730. https://doi.org/10.18203/2320-1770.ijrcog20174015

[8] Washington, C.I., Jamshidi, R., Thung, S.F., Nayeri, U.A., Caughey, A.B. and Werner, E.F. (2015) Timing of Postpartum Intrauterine Device Placement: A Cost-Effectiveness Analysis. Fertility and Sterility, 103, 131-137. https://doi.org/10.1016/j.fertnstert.2014.09.032

[9] Shanavas, A., Jacob, S. and Chellamma, N. (2017) Outcome of Immediate Postpartum Intrauterine Contraceptive Device in Caesarean versus Vaginal Insertion: A Comparative Study. International Journal of Reproduction, Contraception, Obstetrics and Gynecology, 6, 694-699. https://doi.org/10.18203/2320-1770.ijrcog20170407

[10] Singh, U., Sonkar, S., Yadav, P., Dayal, M., Gupta, V. and Saxena, S. (2017) Comparative Evaluation of Postpartum IUCD versus Interval IUCD at a Tertiary Care Centre in Allahabad, India. International Journal of Reproduction, Contraception, Obstetrics and Gynecology, 6, 1534-1538. https://doi.org/10.18203/2320-1770.ijrcog20171423

[11] Kavitha, G., Renukadevi, B. and Ramamoorthy Rathna, S. (2014) A Case Report of Two Unusual Complications Following Intracesarean Insertion of IUD.

[12] Gupta, S., Malik, S., Sinha, R., Shyamsunder, S. and Mittal, M.K. (2014) Association of the Position of the Copper T 380A as Determined by the Ultrasonography Following Its Insertion in the Immediate Postpartum Period with the Subsequent Complications: An Observational Study. Journal of Obstetrics and Gynaecology of India, 64, 349-353. https://doi.org/10.1007/s13224-014-0532-5

[13] Xu, J.X., Reusche, C. and Burdan, A. (1994) Immediate Postplacental Insertion of the Intrauterine Device: A Review of Chinese and the World's Experiences. Advances in Contraception, 10, 71-82. https://doi.org/10.1007/BF01986532

[14] Şevki, Ç., Ayhan, S., Yasemin, Y. and Nuri, D. (2011) Immediate Postplacental Insertion of an Intrauterine Contraceptive Device during Cesarean Section. Contraception, 84, 240-243. https://doi.org/10.1016/j.contraception.2011.01.006

[15] Shukla, M. and Sabuhi Qureshi, C. (2012) Post-Placental Intrauterine Device Inser- 
tion: A Five Year Experience at a Tertiary Care Centre in North India. The Indian Journal of Medical Research, 136, 432.

[16] Jatlaoui, T.C., Marcus, M., Jamieson, D.J., Goedken, P. and Cwiak, C. (2014) Postplacental Intrauterine Device Insertion at a Teaching Hospital. Contraception, 89, 528-533. https://doi.org/10.1016/j.contraception.2013.10.008

[17] Welkovic, S., Costa, L.O., Faúndes, A., de Alencar Ximenes, R. and Costa, C.F. (2001) Post-Partum Bleeding and Infection after Post-Placental IUD Insertion. Contraception, 63, 155-158. https://doi.org/10.1016/S0010-7824(01)00180-9

[18] Evelyn, C., Veronica, A., Erika, B. and Amitasrigowri, M. (2012) Immediate Postplacental IUD Insertion at Cesarean Delivery: A Prospective Cohort Study. Contraception, 86, 102-105. https://doi.org/10.1016/j.contraception.2011.11.019

[19] Hooda, R., Mann, S., Nanda, S., Gupta, A., More, H. and Bhutani, J. (2016) Immediate Postpartum Intrauterine Contraceptive Device Insertions in Caesarean and Vaginal Deliveries: A Comparative Study of Follow-up Outcomes. International Journal of Reproductive Medicine, 2016, Article ID: 7695847. https://doi.org/10.1155/2016/7695847

[20] Levi, E.E., Stuart, G.S., Zerden, M.L., Garrett, J.M. and Bryant, A.G. (2015) Intrauterine Device Placement During Cesarean Delivery and Continued Use 6 Months Postpartum: A Randomized Controlled Trial. Obstetrics and gynecology, 126, 5-11. https://doi.org/10.1097/AOG.0000000000000882

[21] Heller, R., Johnstone, A. and Cameron, S.T. (2017) Routine Provision of Intrauterine Contraception at Elective Cesarean Section in a National Public Health Service: A Service Evaluation. Acta Obstetricia et Gynecologica Scandinavica, 96, 1144-1151. https://doi.org/10.1111/aogs.13178 